\title{
Synthesis and Properties of Polysiloxanes Possessing 9,9-Diarylfluorene Structure in the Main Chain
}

\author{
By Hideki HAYASHI, ${ }^{1}$ Shinichi KAWASAKI, ${ }^{2}$ Kana KOBORI, ${ }^{3}$ \\ Yasuhito KOYAMA, ${ }^{1}$ Shigeo ASAI, ${ }^{1}$ and Toshikazu TAKATA ${ }^{1, *}$
}

Polysiloxanes possessing 9,9-diarylfluorene moieties (F-PSiOs 3 ) were synthesized in $83-91 \%$ yield by the polycondensation of 9,9-bis(hydroxyaryl or hydroxyethoxyphenyl)fluorenes with $\mathrm{Ph}_{2} \mathrm{SiCl}_{2}$ in the presence of pyridine. F-PSiOs with higher molecular weight $\left(M_{\mathrm{n}}\right.$ 19000-32000, $M_{\mathrm{w}}$ 32000-75000) were obtained, when less polar solvents such as toluene and $\mathrm{CCl}_{4}$ were used as the polymerization solvent. The F-PSiOs showed good solubility toward various organic solvents, high 5\% weight loss temperature $\left(T_{\mathrm{d} 5}: 443-544^{\circ} \mathrm{C}\right)$, and lower glass transition temperature $\left(T_{\mathrm{g}}: 100-171^{\circ} \mathrm{C}\right)$ under nitrogen atmosphere rather than 9,9-diarylfluorene-based polymers reported. On the other hand, no melting point $\left(T_{\mathrm{m}}\right)$ was observed owing to the amorphous nature of F-PSiOs. Dynamic viscoelasticity of F-PSiO film was also measured to evaluate the thermal behavior. The transmittance of F-PSiOs in the film state (thickness: $62-70 \mu \mathrm{m}$ ) reached over $90 \%$ in the visible region. The F-PSiOs exhibited remarkably high refractive index values in a range of $1.64-1.66$ at $589 \mathrm{~nm}$ in addition to sufficiently low birefringence values, probably due to the cardo structure of the fluorene moiety placed in the main chain. KEY WORDS: Cardo Structure / Polysiloxane / Refractive Index / Birefringence / Solubility / Thermal Stability / Processability /

9,9-Diarylfluorene-based transparent resins are an intriguing class of polymers owing to their high refractive index ${ }^{1-6}$ and low birefringence. ${ }^{7-12}$ The optical properties were originated from many aromatic rings of the 9,9-diarylfluorene moiety as so-called "cardo structure," in which each aromatic ring occupies different planes. In addition, such polymers exhibit other characteristic properties including fine dispersing ability for inorganic fillers, ${ }^{13,14}$ good solubility toward organic solvents, ${ }^{15}$ high thermal stability, ${ }^{16-19}$ and so on. ${ }^{20-24} \mathrm{Al}-$ though several studies directed toward optical use of 9,9diarylfluorene-based high performance polymers have been reported, the polymers often suffer from low heat-processability due to the high glass transition temperature $\left(T_{\mathrm{g}}\right){ }^{16-19}$ As a potential solution to this issue, we postulated that the siloxane linkage in the main chain would serve as an effective linker, because polysiloxanes generally exhibit low $T_{\mathrm{g}}$ in addition to high thermal stability. ${ }^{25-27}$ While Nakamura et al. first reported the synthesis of polysiloxanes possessing 9,9diarylfluorene structure by the elaborations with dianilinodiphenylsilane, ${ }^{27}$ there remains ample opportunities directed toward simple polymerization protocols for polysiloxanes and the optical applications.

Herein, we describe the synthesis of polysiloxanes (FPSiOs) bearing 9,9-diarylfluorene moieties in the main chain by the polycondensation of 9,9-diarylfluorene derivatives (Figure 1) and commercially available $\mathrm{Ph}_{2} \mathrm{SiCl}_{2}$. Several typical optical properties such as transparency, refractive index, and birefringence of the F-PSiOs are also evaluated in addition to the thermal properties and solubility.

\section{EXPERIMENTAL}

\section{Materials and Methods}

9,9-Bis(4-hydroxy-3-methylphenyl)fluorene (1a), 9,9-bis(4hydroxyphenyl)fluorene (1b), and 9,9-bis[4-(2-hydroxyethoxy)phenyl]fluorene (1c) (provided by Osaka Gas Co., Ltd.) were used after drying in vacuo at $100^{\circ} \mathrm{C}$ for $5 \mathrm{~h}$. All solvents were dried over freshly activated molecular sieves $4 \mathrm{~A}$. Commercially available materials and solvents including $\mathrm{Ph}_{2} \mathrm{SiCl}_{2}$ (Wako Pure Chemical Industries, Ltd.) were used without further purification.

${ }^{1} \mathrm{H}(400 \mathrm{MHz})$ and ${ }^{29} \mathrm{Si}(79.3 \mathrm{MHz})$ NMR spectra were recorded on a JEOL AL-400 spectrometer using $\mathrm{CDCl}_{3}$ as the solvent and tetramethylsilane as the internal standard. Molecular weight and its distribution were measured by gel permeation chromatography (GPC) on a JASCO Gulliver system equipped with two consecutive liner polystyrene gel columns (TOSOH TSKgel G2000HXL and GMHXL) at $30^{\circ} \mathrm{C}$, eluted with $\mathrm{CHCl}_{3}$ at a flow rate of $0.85 \mathrm{~mL} / \mathrm{min}$, and calibrated using polystyrene standards. IR spectra were recorded on a JASCO FT/IR-230 spectrometer. Thermogravimetry (TG) was performed on a Shimadzu TGA-50 instrument at a heating rate of $10^{\circ} \mathrm{C} / \mathrm{min}$ under $\mathrm{N}_{2}$ atmosphere (flow rate of $50 \mathrm{~mL} / \mathrm{min}$ ) to determine decomposition temperature $T_{\mathrm{d} 5}$ at which $5 \%$ weight loss was observed. Differential scanning calorimetry (DSC) was carried out using a Shimadzu DSC-60 instrument at a heating rate of $10^{\circ} \mathrm{C} / \mathrm{min}$ under $\mathrm{N}_{2}$ atmosphere (flow rate of $50 \mathrm{~mL} / \mathrm{min}$ ) to determine glass transition temperature $T_{\mathrm{g}}$. Dynamic mechanical properties of polymer film were evaluated in a temperature

\footnotetext{
${ }_{1}^{1}$ Department of Organic and Polymeric Materials, Tokyo Institute of Technology, 2-12-1, Ookayama, Meguro, Tokyo 152-8552, Japan

${ }^{2}$ Energy Technology Laboratories, Osaka Gas Co., Ltd., Konohana, Osaka 554-0051, Japan

${ }^{3}$ Fine Materials Department, Osaka Gas Co., Ltd., Konohana, Osaka 554-0051, Japan

*To whom correspondence should be addressed (Tel: +81-3-5734-2898, Fax: +81-3-5734-2888, E-mail: takata.t.ab@m.titech.ac.jp).
} 


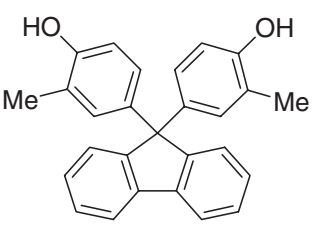

$1 \mathrm{a}$

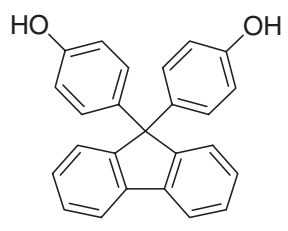

$1 \mathrm{~b}$

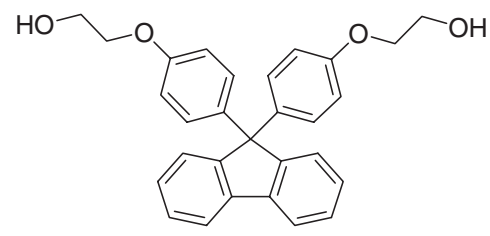

$1 c$

Figure 1. Chemical structures of 9,9-diarylfluorene diol monomers used in this work.

range from room temperature to $115^{\circ} \mathrm{C}$ by using an ITDVA200s (ITK Co., Ltd, Japan). The measurement was conducted in the oscillatory tensile mode at a frequency of $10 \mathrm{~Hz}$ and a heating rate of $5{ }^{\circ} \mathrm{C} / \mathrm{min}$. The dimension of a rectangular specimen was $4.8 \mathrm{~mm}$ in width and $600 \mu \mathrm{m}$ in thickness and the distance between clamps was $1.5 \mathrm{~cm}$, respectively. Transmittance of polymer films was evaluated by a UV-visible spectrophotometer (UV-550, JASCO) with the scanning range from $300 \mathrm{~nm}$ to $800 \mathrm{~nm}$. Refractive indices of polymers were measured with an Abbe refractometer (DRM2/1550, ATAGO Co., Ltd). Birefringences of the film were evaluated by taking the picture of the film placed between two cross axes polarizing films. Retardations were measured by polarized optical microscopy (OPTIPHOTO-POL, Nikon Co., Ltd) under the cross-Nicols $(546 \mathrm{~nm})$.

Typical Experimental Procedure for the Reaction of 9,9-Bis(4hydroxyphenyl)fluorene (1b) and $\mathbf{P h}_{2} \mathbf{S i C l}_{2}$ (2). ${ }^{28}$ To a mixture of 9,9-bis(4-hydroxyphenyl) fluorene (1b, 7.74 g, $22.1 \mathrm{mmol}$ ) and pyridine $(5.0 \mathrm{~mL}, 62 \mathrm{mmol})$ in toluene $(14 \mathrm{~mL})$ was added dropwise a solution of $\mathrm{Ph}_{2} \mathrm{SiCl}_{2}(2,5.59 \mathrm{~g}, 22.1 \mathrm{mmol})$ in toluene $(6 \mathrm{~mL})$ at room temperature under an argon atmosphere. After stirring at $40^{\circ} \mathrm{C}$ for $8 \mathrm{~h}$, the mixture was cooled to room temperature, and diluted with toluene to precipitate pyridinium hydrochloride, which was filtered off. The filtrate was washed with $7.7 \%$ aqueous pyridine, and then poured into $\mathrm{MeOH}$. The precipitates formed were collected by filtration, and the solid product was dried in vacuo at room temperature for $1 \mathrm{~d}$ to give F-PSiO $\mathbf{3 b}(9.73 \mathrm{~g}, 83 \%)$ as a white solid; $M_{\mathrm{n}}$ 21000, $M_{\mathrm{w}} 40000, M W D 1.9 ; T_{\mathrm{g}} 166^{\circ} \mathrm{C}, T_{\mathrm{d} 5} 544^{\circ} \mathrm{C} ;{ }^{1} \mathrm{H}$ NMR $\left(400 \mathrm{MHz}, \mathrm{CDCl}_{3}, 298 \mathrm{~K}\right) \delta 7.65(\mathrm{~d}, 4 \mathrm{H}, J=7.4 \mathrm{~Hz}), 7.61(\mathrm{~d}$, $2 \mathrm{H}, J=7.6 \mathrm{~Hz}), 7.36(\mathrm{t}, 2 \mathrm{H}, J=7.6 \mathrm{~Hz}), 7.27(\mathrm{t}, 4 \mathrm{H}, J=$ $7.4 \mathrm{~Hz}), 7.19(\mathrm{t}, 2 \mathrm{H}, J=7.4 \mathrm{~Hz}), 7.15(\mathrm{~d}, 2 \mathrm{H}, J=7.6 \mathrm{~Hz})$, $7.07(\mathrm{t}, 2 \mathrm{H}, J=7.6 \mathrm{~Hz}), 6.82(\mathrm{~d}, 4 \mathrm{H}, J=8.2 \mathrm{~Hz}), 6.64(\mathrm{~d}, 4 \mathrm{H}$, $J=8.2 \mathrm{~Hz}) \mathrm{ppm}:{ }^{29} \mathrm{Si} \mathrm{NMR}\left(79.3 \mathrm{MHz}, \mathrm{CDCl}_{3}, 298 \mathrm{~K}\right) \delta$ -39.1 ppm; IR (neat) 3033, 1604, 1504, 1447, 1429, 1241, $1173,1125,1015,915,826,737,718,697,630 \mathrm{~cm}^{-1}$.

F-PSiO 3a. A white solid (91\%); $M_{\mathrm{n}} 19000, M_{\mathrm{w}} 32000, M W D$ $1.7 ; T_{\mathrm{g}} 171^{\circ} \mathrm{C}, T_{\mathrm{d} 5} 528{ }^{\circ} \mathrm{C} ;{ }^{1} \mathrm{H} \mathrm{NMR}\left(400 \mathrm{MHz}, \mathrm{CDCl}_{3}, 298 \mathrm{~K}\right)$ $\delta 7.8-7.5(\mathrm{~m}, 6 \mathrm{H}), 7.5-6.9(\mathrm{~m}, 12 \mathrm{H}), 6.85(\mathrm{~s}, 2 \mathrm{H}), 6.57(\mathrm{~s}, 4 \mathrm{H})$, $2.03(\mathrm{~s}, 6 \mathrm{H}) \mathrm{ppm} ;{ }^{29} \mathrm{Si} \mathrm{NMR}\left(79.3 \mathrm{MHz}, \mathrm{CDCl}_{3}, 298 \mathrm{~K}\right) \delta$ -38.3 ppm: IR (neat) 3049, 2919, 1604, 1590, 1497, 1447, 1429, 1254, 1125, 943, 809, 741, 717, 698, $647 \mathrm{~cm}^{-1}$.

F-PSiO 3c. A white solid (85\%); $M_{\mathrm{n}} 32000, M_{\mathrm{w}} 75000, M W D$ 2.3; $T_{\mathrm{g}} 100{ }^{\circ} \mathrm{C}, T_{\mathrm{d} 5} 443{ }^{\circ} \mathrm{C} ;{ }^{1} \mathrm{H}$ NMR $\left(400 \mathrm{MHz}, \mathrm{CDCl}_{3}, 298 \mathrm{~K}\right)$ $\delta 7.68(\mathrm{~d}, 2 \mathrm{H}, J=7.4 \mathrm{~Hz}), 7.62(\mathrm{~d}, 4 \mathrm{H}, J=7.4 \mathrm{~Hz}), 7.4-7.1$ $(\mathrm{m}, 12 \mathrm{H}), 7.03(\mathrm{~d}, 4 \mathrm{H}, J=8.7 \mathrm{~Hz}), 6.65(\mathrm{~d}, 4 \mathrm{H}, J=8.7 \mathrm{~Hz})$, $4.04(\mathrm{t}, 4 \mathrm{H}, J=4.8 \mathrm{~Hz}), 3.96(\mathrm{t}, 4 \mathrm{H}, J=4.8 \mathrm{~Hz}) \mathrm{ppm}$; IR (neat) 3068, 2933, 2876, 1607, 1507, 1448, 1429, 1373, 1290, $1250,1179,1125,1064,971,916,823,745,718,701$, $667 \mathrm{~cm}^{-1}$

Film Preparation. Polymer films of the F-PSiOs for the evaluation of refractive index and birefringence were prepared by a spincoating method using the toluene solutions of the corresponding polymers at room temperature. The films for the evaluation of transmittance were prepared by a casting method using the toluene solutions of the corresponding polymers at room temperature.

\section{RESULTS AND DISCUSSION}

\section{Synthesis and Structure of F-PSiOs}

Since we previously used 9,9-bis(4-hydroxy-3-methylphenyl)fluorene (1a) for the preparation of high performance poly(ether-ketone)s with excellent optical properties, ${ }^{12}$ we have first examined 1a as the diol monomer for the preparation of F-PSiOs. Polycondensation reactions of $\mathbf{1 a}(11.0 \mathrm{mmol})$ with commercially available dichlorodialkylsilanes $(11.0 \mathrm{mmol})$ in the presence of pyridine $(30 \mathrm{mmol})$ were conducted in various solvents $(1.1 \mathrm{M})$. After the initial unfruitful attempts utilizing $\mathrm{Me}_{2} \mathrm{SiCl}_{2}$, we found that the preparation of stable polysiloxane was achieved by using $\mathrm{Ph}_{2} \mathrm{SiCl}_{2}$ (2) probably owing to the more acid-resistant $\mathrm{Si}-\mathrm{O}$ linkage (Scheme 1).

Various solvents were used as polymerization solvents. The results are summarized in Table I. It turned out that toluene and $\mathrm{CCl}_{4}$ used as the suitable less polar solvents (entries 5 and 6) gave a highly viscous mixture including the corresponding polysiloxane 3a $\left(M_{\mathrm{n}} 7900-8000, M_{\mathrm{w}} 14000-15000\right)$ and pyridinium hydrochloride as precipitates. Meanwhile, the polycondensation in polar solvents such as THF and $\mathrm{CH}_{2} \mathrm{Cl}_{2}$ afforded lower molecular weight polysiloxane $3 \mathbf{a}\left(M_{\mathrm{n}} 4700\right.$ 5300, $M_{\mathrm{w}}$ 7500-9000; entries 1 and 2) than those in less polar solvents. After considerable experimental work, polysiloxane 3a with relatively high molecular weight $\left(M_{\mathrm{n}} 19000, M_{\mathrm{w}}\right.$ $32000, M W D$ 1.7) enough to evaluate the optical properties was obtained by the polymerization in $\mathrm{CCl}_{4}$ at $80^{\circ} \mathrm{C}$ for $18 \mathrm{~h}$ (entry 7).

Considering the moderate reactivity of 1a, we planned to exploit both 9,9-bis(4-hydroxyphenyl)fluorene 1b without the methyl substituents at the ortho position to the phenolic $\mathrm{OH}$ group and 9,9-bis[4-(2-hydroxyethoxy)phenyl]fluorene 1c as the alcoholic monomer, which could hopefully serve as the more reactive monomers owing to the less steric hindrance. 


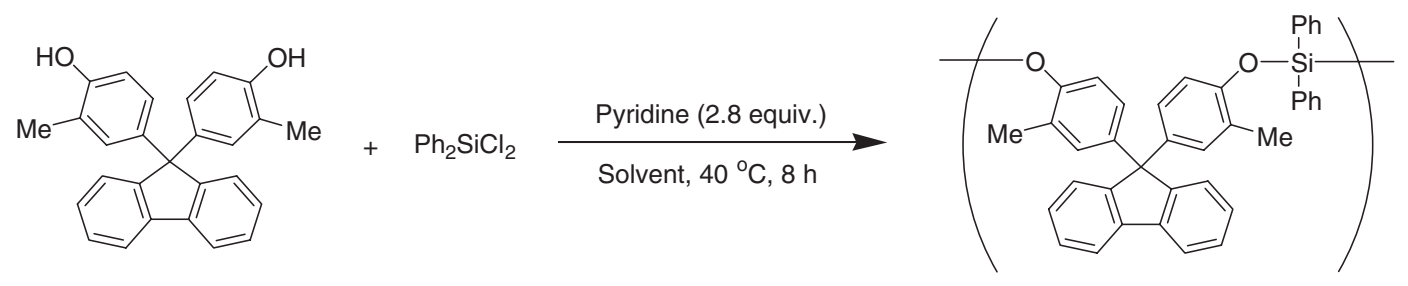

$1 a$

2 (1.0 equiv.)

$3 a$

Scheme 1.<smiles>Oc1ccc(C2(c3ccc(O)cc3)c3ccccc3-c3ccccc32)cc1</smiles>

$1 b$

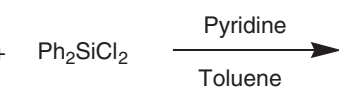

2

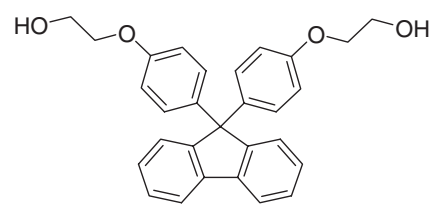

$1 c$

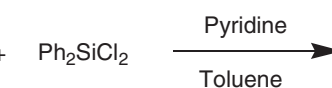

2

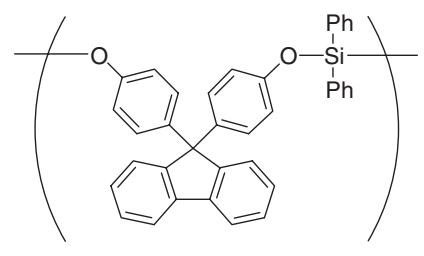

3b
Table I. Effect of solvent on the polycondensation of bisphenol 1a and $\mathrm{Ph}_{2} \mathrm{SiCl}_{2} 2^{\mathrm{a}}$

\begin{tabular}{cccccc}
\hline Entry & Solvent & Yield $^{\mathrm{b}} / \%$ & $M_{\mathrm{n}}^{\mathrm{c}}$ & \multicolumn{1}{c}{$M_{\mathrm{w}}^{\mathrm{c}}$} & $M W D^{\mathrm{c}}$ \\
\hline 1 & $\mathrm{THF}$ & 86 & 4700 & 7500 & 1.6 \\
2 & $\mathrm{CH}_{2} \mathrm{Cl}_{2}$ & 84 & 5300 & 9000 & 1.7 \\
3 & $\mathrm{CHCl}_{3}$ & 78 & 4500 & 7200 & 1.6 \\
4 & $\mathrm{ClCH}_{2} \mathrm{CH}_{2} \mathrm{Cl}$ & 80 & 6800 & 12000 & 1.8 \\
5 & $\mathrm{CCl}_{4}$ & 83 & 8000 & 14000 & 1.8 \\
6 & $\mathrm{Toluene}_{7}^{\text {d }}$ & 81 & 7900 & 15000 & 1.9 \\
\hline
\end{tabular}

${ }^{\mathrm{a}} \mathrm{A}$ mixture of $1 \mathrm{a}(11.0 \mathrm{mmol})$ and $2(11.0 \mathrm{mmol})$ was heated in the presence of pyridine $(30 \mathrm{mmol})$ in toluene $(10 \mathrm{~mL})$ at $40^{\circ} \mathrm{C}$ for $8 \mathrm{~h}$. bYield of $\mathrm{MeOH}$-insolble part. ${ }^{\mathrm{c} E s t i m a t e d}$ by GPC using polystyrene standards (eluent: $\mathrm{CHCl}_{3}$ ). ${ }^{\mathrm{d}}$ The reaction was performed at $80^{\circ} \mathrm{C}$ for $18 \mathrm{~h}$.

Since the use of $\mathrm{CCl}_{4}$ as a solvent gave a good result in the synthesis of $\mathbf{3 a}$, we examined the use of less polar solvents such as toluene in place of $\mathrm{CCl}_{4}$ from a viewpoint of green chemistry (Scheme 2). Relationship between polymer molecular weight and reaction time in the polycondensation to $\mathbf{3 b}$ and 3c was evaluated at $40^{\circ} \mathrm{C}$ and $100^{\circ} \mathrm{C}$. The results are shown in Figure 2. During the polymerization, the molecular weights of $\mathbf{3 b}$ and $\mathbf{3 c}$ initially increased but then decreased except for the polymerization of $1 \mathrm{c}$ at $40{ }^{\circ} \mathrm{C}$. These results suggest that both the formation and the cleavage of $\mathrm{Si}-\mathrm{O}$ bond of the polymer

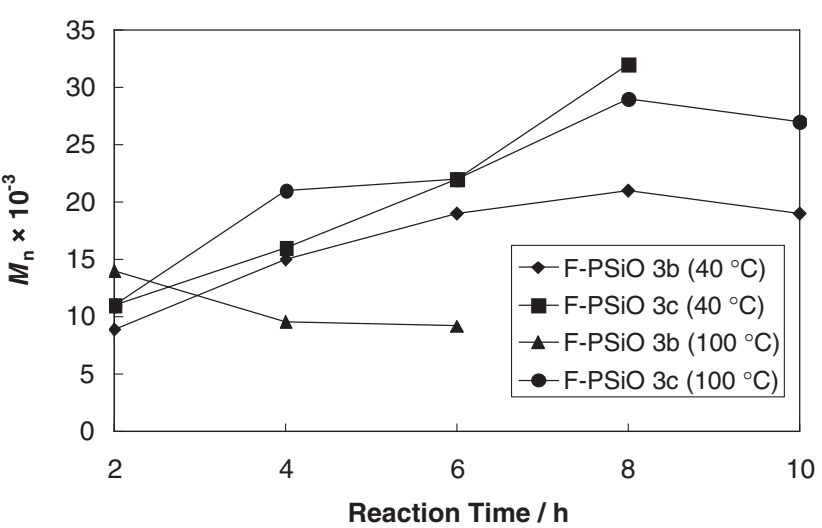

Figure 2. Effect of reaction temperature and time on the molecular weight of F-PSiOs $\mathbf{3 b}$ and $\mathbf{3 c}$ in the polymerization in toluene $(1.1 \mathrm{M})$ in the presence of pyridine ( 2.8 equiv.).

chain proceed competitively. To clarify the degradation process, the reduction in polymer molecular weight by additive was examined using F-PSiO 3b ( $M_{\mathrm{n}}$ 16000) (Table II). Treatment of $\mathbf{3 b}$ with either pyridine in toluene and pyridinium hydrochloride in THF resulted in the considerable decrease in molecular weight due to the cleavage of $\mathrm{Si}-\mathrm{O}$ bond, undoubtedly by nucleophilic attack of pyridine or chloride anion at the 

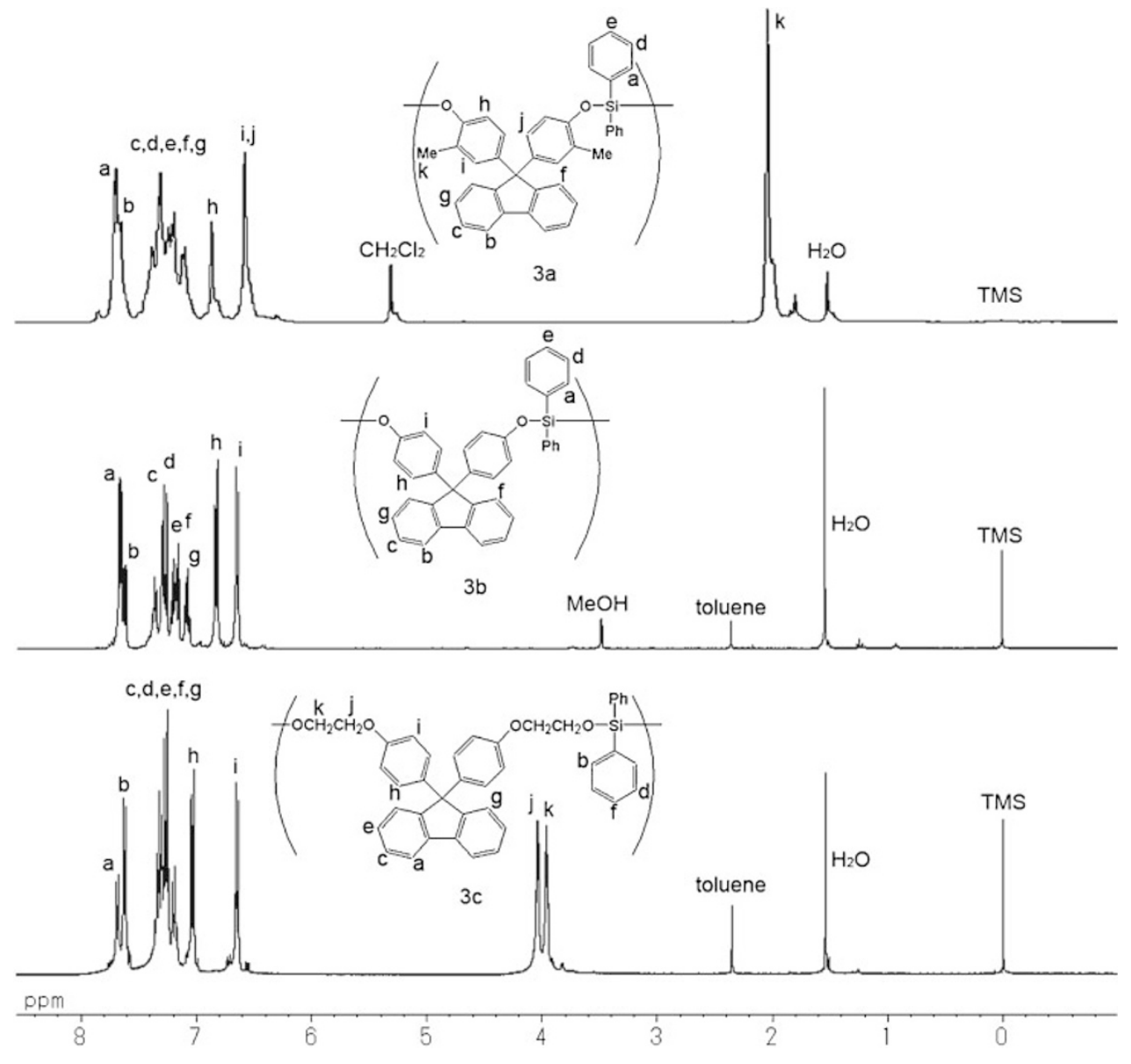

Figure 3. ${ }^{1} \mathrm{H}$ NMR spectra $\left(400 \mathrm{MHz}, \mathrm{CDCl}_{3}, 298 \mathrm{~K}\right)$ of F-PSiOs $\mathbf{3 a}, \mathbf{3 b}$ and $\mathbf{3 c}$.

Table II. Effect of additive on the reduction of polymer molecular weight ${ }^{\mathrm{a}}$

\begin{tabular}{ccccr}
\hline Entry & Additive & Solvent & Temp. $/{ }^{\circ} \mathrm{C}$ & \multicolumn{1}{c}{$M_{\mathrm{n}}{ }^{\mathrm{b}}$} \\
\hline 1 & - & toluene & 100 & 14000 \\
2 & pyridine & toluene & 100 & 2400 \\
3 & pyridinium hydrochloride & toluene & 100 & 13000 \\
4 & pyridinium hydrochloride & THF & 50 & 4300 \\
\hline
\end{tabular}

${ }^{a}$ A mixture of F-PSiO $3 \mathbf{b}\left(M_{\mathrm{n}} 16000,1.06 \mathrm{~g}\right)$ and an additive (pyridine $(0.25 \mathrm{~mL})$ or pyridinium hydrochloride $(690 \mathrm{mg})$ ) was heated in a solvent $(10 \mathrm{~mL})$ for $12 \mathrm{~h}$. ${ }^{\mathrm{b}} \mathrm{GPC}$ data based on the polystyrene standards (eluent: $\mathrm{CHCl}_{3}$ ).

silicon atom (entries 2 and 4). On the other hand, the reduction in polymer molecular weight by the addition of pyridinium hydrochloride in toluene was sluggish probably owing to the low solubility of pyridinium hydrochloride toward toluene (entry 3). The results suggest that the use of less polar solvents such as toluene and $\mathrm{CCl}_{4}$ controls the reduction in polymer molecular weight in the synthesis of F-PSiOs. Although the polymerization of $\mathbf{1 b}$ at $0{ }^{\circ} \mathrm{C}$ afforded a remarkably highly viscous mixture, the polymer molecular weight was low (3b: $M_{\mathrm{n}} 2800, M_{\mathrm{w}} 4800$ ), because of the low solubility behavior of the polymer to toluene at $0{ }^{\circ} \mathrm{C}$. After considerable experimental work based on the knowledge thus obtained, we decided the optimal condition to obtain polysiloxanes $\mathbf{3 b}\left(M_{\mathrm{n}} 21000, M_{\mathrm{w}}\right.$
40000, $M W D$ 1.9) and 3c $\left(M_{\mathrm{n}} 32000, M_{\mathrm{w}} 75000, M W D 2.3\right)$ suitable for the film preparation. Namely, the polymerizations were conducted in toluene at $40^{\circ} \mathrm{C}$ for $8 \mathrm{~h}$, contrary to extremely elevated temperature $\left(220^{\circ} \mathrm{C}\right)$ in the case of dianilinosilane system. ${ }^{27}$

Figures 3 and 4 show ${ }^{1} \mathrm{H}$ NMR and ${ }^{29} \mathrm{Si}$ NMR spectra of F-PSiOs 3. In the ${ }^{1} \mathrm{H}$ NMR spectra, all aromatic signals of $\mathbf{3}$ appeared sharply, which suggested a low degree of disorderness in polymer structure (Figure 3). In ${ }^{29} \mathrm{Si}$ NMR spectra, the sharp signal appeared around $-40 \mathrm{ppm}$ was assignable to that of $\mathrm{Si}$ atom of $\mathrm{Ph}_{2} \mathrm{Si}(\mathrm{OAr})_{2}$, whereas signals corresponding to neither $\mathrm{Ph}_{2} \mathrm{SiCl}_{2}$ nor $\mathrm{Ph}_{2} \mathrm{SiCl}(\mathrm{OAr}$ ) was observed (Figure 4). IR spectral data also supported the polysiloxane structure; a medium absorption band at $1429 \mathrm{~cm}^{-1}$ and a strong band at $1125 \mathrm{~cm}^{-1}$ corresponding to $\mathrm{Si}-\mathrm{C}$ linkage in addition to strong broad absorptions at $1100-1000 \mathrm{~cm}^{-1}$ and $1300-1200 \mathrm{~cm}^{-1}$ for $\mathrm{Si}-\mathrm{O}$ linkage. ${ }^{28}$

\section{Properties of F-PSiOs}

Thermal and optical properties of $\mathbf{3 a}\left(M_{\mathrm{n}} 19000, M_{\mathrm{w}} 32000\right.$, $M W D$ 1.7), 3b $\left(M_{\mathrm{n}} 21000, M_{\mathrm{w}} 40000, M W D 1.9\right)$, and $\mathbf{3 c}\left(M_{\mathrm{n}}\right.$ 32000, $M_{\mathrm{w}}$ 75000, MWD 2.3) were examined. The F-PSiO films for the measurement were prepared by casting from a toluene solution (film thickness: $62-70 \mu \mathrm{m}$ ). 


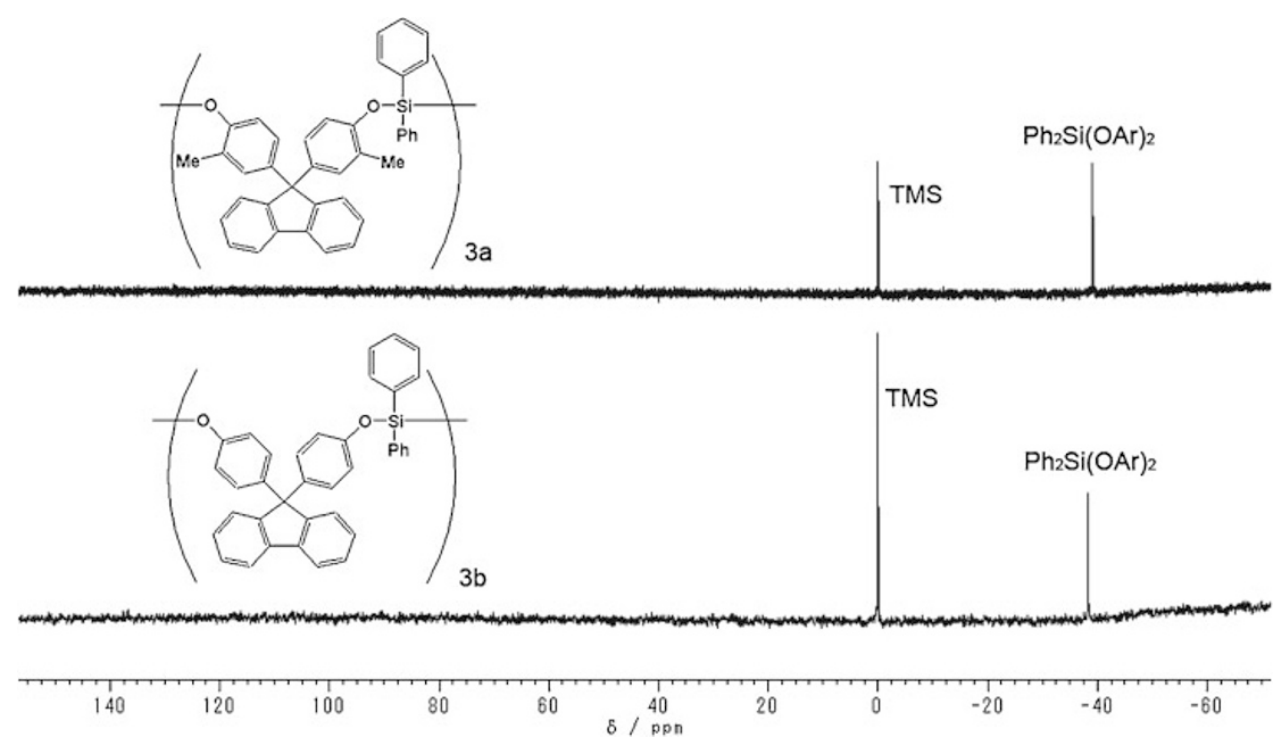

Figure 4. ${ }^{29} \mathrm{Si} \mathrm{NMR} \mathrm{spectra}\left(79.3 \mathrm{MHz}, \mathrm{CDCl}_{3}, 298 \mathrm{~K}\right)$ of F-PSiOs $\mathbf{3 a}$ and $\mathbf{3 b}$.

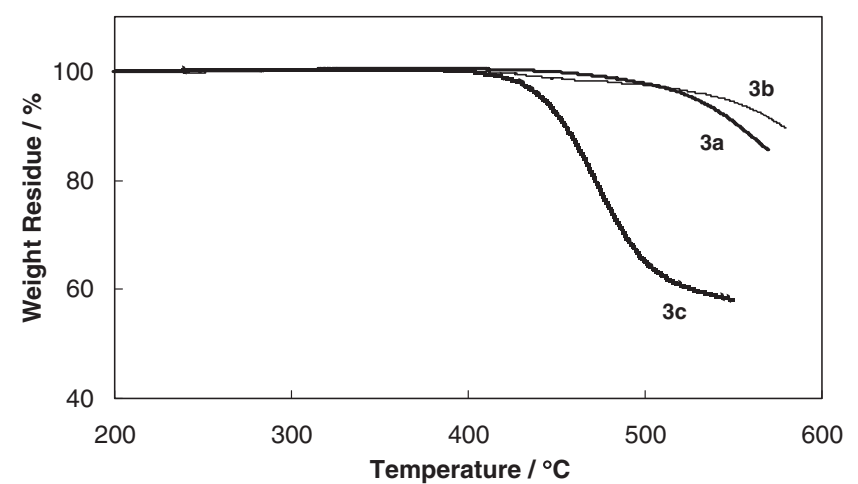

Figure 5. TGA results of F-PSiOs, measured at a heating rate $10^{\circ} \mathrm{C} / \mathrm{min}$ in $\mathrm{N}_{2}$ atmosphere.

\section{Thermal Property}

The thermal properties were evaluated by TGA and DSC (Figures 5 and 6). The decomposition temperatures $\left(T_{\mathrm{d} 5}\right)$ were very high; $528^{\circ} \mathrm{C}(3 \mathbf{a}), 544^{\circ} \mathrm{C}(3 \mathbf{b})$, and $443^{\circ} \mathrm{C}(3 \mathbf{c})$, which clearly depended on the structure of the siloxane linkage of the polymers. The high thermal stability probably comes from the strong Si-O covalent bond: bond energy of Si-O is $368 \mathrm{~kJ} / \mathrm{mol}$, while that of $\mathrm{C}-\mathrm{O}$ is $336 \mathrm{~kJ} / \mathrm{mol}$. On the other hand, no melting point $\left(T_{\mathrm{m}}\right)$ was observed in this case, clearly suggesting the amorphous nature of the F-PSiOs. $T_{\mathrm{g}} \mathrm{s}$ of the F-PSiOs were sufficiently low as expected according to the literature: ${ }^{27}$ $171^{\circ} \mathrm{C}(3 \mathbf{a}), 166^{\circ} \mathrm{C}(3 \mathbf{b})$, and $100{ }^{\circ} \mathrm{C}$ (3c), unambiguously due to the flexible siloxane main chain structure. The low $T_{\mathrm{g}}$ for $3 \mathbf{c}$ also suggests that $T_{\mathrm{g}}$ of the F-PSiO was controlled easily by controlling the structure of the spacer between the diarylfluorene and the siloxane moieties.

\section{Dynamic Viscoelasticity of F-PSiO Film}

Dynamic mechanical properties of F-PSiO 3c film was evaluated in a temperature range from room temperature to

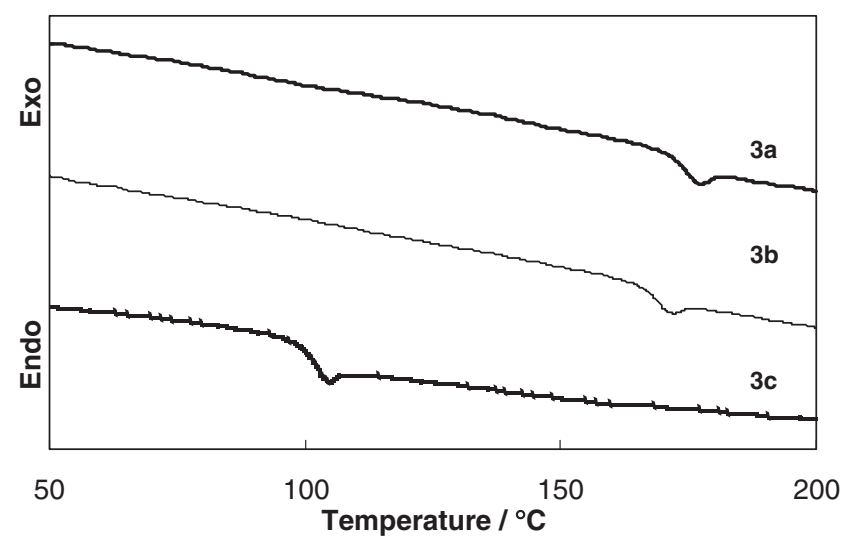

Figure 6. DSC results of $\mathrm{F}-\mathrm{PSiOs}$, measured at a heating rate $10^{\circ} \mathrm{C} / \mathrm{min}$ in $\mathrm{N}_{2}$ atmosphere.

$115^{\circ} \mathrm{C}$. Figure 7 shows the temperature dependence of the dynamic viscoelastic properties such as tensile storage modulus $E^{\prime}$ and $\tan \delta$. The results suggested that the plateau region in $E^{\prime}$ appeared until $80^{\circ} \mathrm{C}$, while the peak top of the $\tan \delta$ curve was $94{ }^{\circ} \mathrm{C}$, mostly corresponding to the $T_{\mathrm{g}}$ of F-PSiO $3 \mathbf{c}$ evaluated by DSC.

\section{Solubility}

The solubility toward various organic solvents was evaluated. The results are summarized in Table III. All three polymers $\mathbf{3}$ were highly soluble in typical organic solvents such as toluene, $\mathrm{CHCl}_{3}$, and $\mathrm{THF}$, even though they consist mostly of aromatics. The unusually high solubility observed here presumably comes from the special structure of 9,9diarylfluorene moieties, so-called "cardo structure" and the flexible $\mathrm{Si}-\mathrm{O}$ linkage in the main chain, as mentioned above. ${ }^{15}$ The high solubility along with the good thermal properties of the F-PSiOs seems to enhance their processability. 


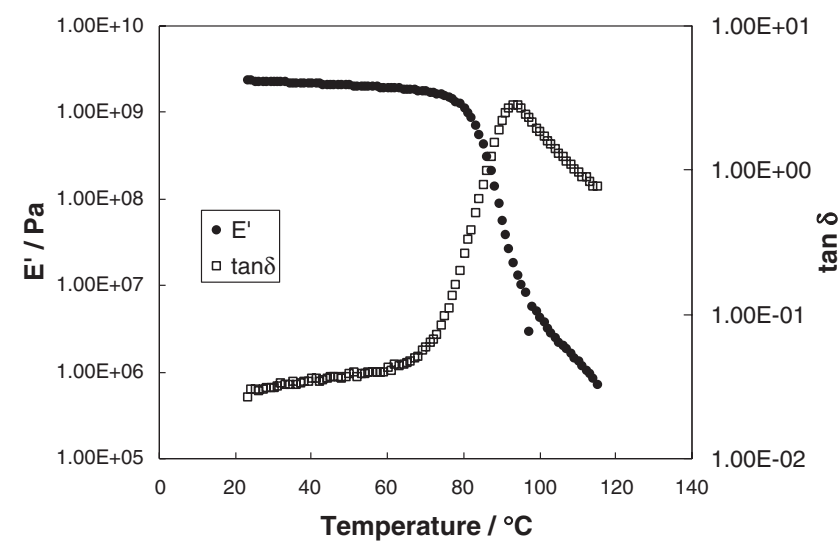

Figure 7. Viscoelastic property of F-PSiO $3 \mathbf{c}$ in a range from room temperature to $115^{\circ} \mathrm{C}$.

Table III. Solubility behavior of F-PSiOs to organic solvents ${ }^{a}$

\begin{tabular}{cccccccc}
\hline F-PSiO & $\mathrm{CHCl}_{3}$ & THF & toluene & acetone & $\mathrm{MeCN}$ & $\mathrm{MeOH}$ & hexane \\
\hline 3a & ++ & ++ & ++ & + & - & + & - \\
3b & ++ & ++ & ++ & - & - & - & - \\
3c & ++ & ++ & ++ & - & - & - & - \\
\hline
\end{tabular}

${ }^{\text {a F}-P S i O ~}(100 \mathrm{mg})$ was added to a solvent $(1 \mathrm{~mL})$ and stirred at room temperature. ++ , soluble; + , partially soluble; - , insoluble.

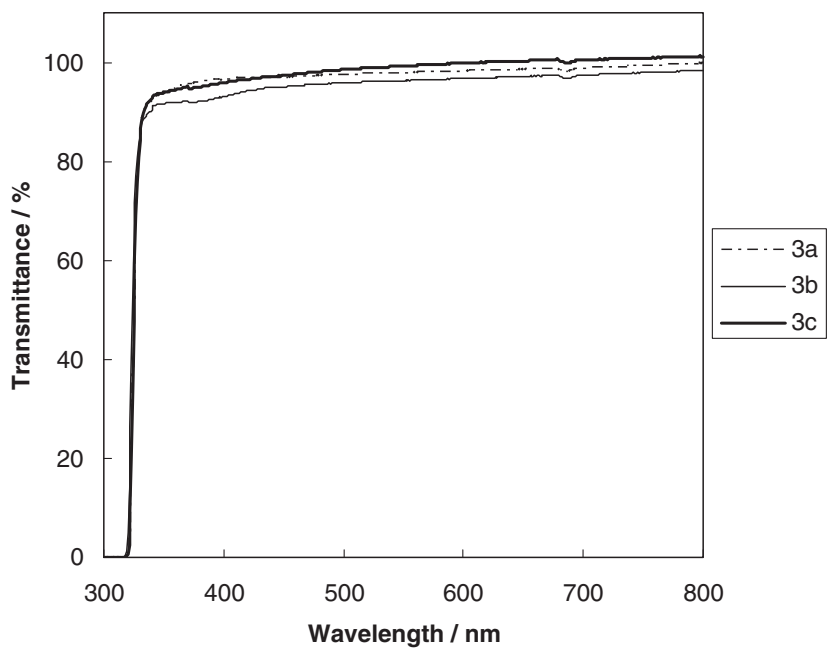

Figure 8. Transmittance of $\mathbf{3}$ in film state measured by UV-vis spectrometer (film thickness: $62-70 \mu \mathrm{m}$ ).

\section{Transparency}

The transmittance of the all films reached $c a$. $90 \%$ over $340 \mathrm{~nm}$, and gradually increased with increase of wavelength in the visible light region (Figure 8). The high transparency of the F-PSiOs probably results from their amorphous nature owing to the cardo structure of the 9,9-diarylfluorene moiety, and is consistent with the largely decreased interchromophore interaction in or within the polymer chain.

\section{Refractive Index}

The refractive indices of the F-PSiOs were measured using their thin films which were obtained by the spincoating method
Table IV. Refractive index of F-PSiOs $3^{\mathrm{a}}$

\begin{tabular}{ccc}
\hline \multirow{2}{*}{ F-PSiO } & \multicolumn{2}{c}{ Refractive Index } \\
\cline { 2 - 3 } & $589 \mathrm{~nm}$ & $656 \mathrm{~nm}$ \\
\hline 3a & 1.65 & 1.64 \\
3b & 1.64 & - \\
3c & 1.66 & 1.66 \\
\hline \multirow{2}{*}{ a Refractive indices of the polymer samples were measured by an Abbe }
\end{tabular}

refractometer (film thickness: $440-460 \mu \mathrm{m}$ ).

Table V. Degree of retardation of F-PSiOs $3^{a}$

\begin{tabular}{ccc}
\hline \multirow{2}{*}{ F-PSiO } & \multicolumn{2}{c}{ Degree of Retardation $/ \mathrm{nm}$} \\
\cline { 2 - 3 } & undrawn & drawn $^{\mathrm{b}}$ \\
\hline 3a & 0.0 & - \\
3b & 0.0 & - \\
3c & 0.0 & 0.0 \\
\hline
\end{tabular}

${ }^{a}$ Retardation was measured by a polarized optical microscopy under the cross Nicols with the light wavelength of $546 \mathrm{~nm}$. ${ }^{\text {b}}$ The film was drawn at $100-120^{\circ} \mathrm{C}$. Drawn ratio was 2.0 .

using toluene solutions of the polymers at room temperature. The results are summarized in Table IV. The refractive index values were sufficiently high as polymer consisting only of $\mathrm{C}$, $\mathrm{H}$, and $\mathrm{O}$ atoms: 1.65 (3a), $1.64(3 \mathbf{b})$ and $1.66(3 \mathbf{c})$ at a typical wavelength of $589 \mathrm{~nm}$. The high refractive index values of the F-PSiOs are certainly attributable to the polynuclear aromatic main chain consisting of both the 9,9-diarylfluorene and the diphenylsilyl moieties. Meanwhile, it can be concluded that the flexible alkyl chain as the spacer moiety of $\mathbf{3 c}$ enables the dense packing of polymer chains resulting in the high refractive index.

\section{Birefringence}

The birefringence of the F-PSiOs 3 was evaluated using both the drawn and undrawn films. Degree of retardation of visible light at $546 \mathrm{~nm}$ in the F-PSiOs was $0.0 \mathrm{~nm}$ in both drawn and undrawn states (Table V). Very low or zero birefringence observed is attributed to the cardo structure of the 9,9diarylfluorene moiety in the main chain as mentioned previously. ${ }^{7-12}$ The fluorene moiety and the two phenyl groups at the C9-position of the fluorene group occupy different planes and are crossed at the precise angle that renders the structure most stable. Placing the aromatic rings on the different planes might disturb their one-directional folding, and thereby the optical anisotropy of the F-PSiOs disappears.

\section{SUMMARY}

This paper has disclosed the simple polycondensation of diphenolic or alcoholic 9,9-diarylfluorene derivatives with $\mathrm{Ph}_{2} \mathrm{SiCl}_{2}$ and the characteristic properties of the resulting polymers (F-PSiOs 3a-3c). The F-PSiOs showed their relatively high $T_{\mathrm{d} 5}$, low $T_{\mathrm{g}}$, and high solubility, which seems to enhance their processability. The transparent films of the FPSiOs exhibited remarkably high refractive index values in a 
range of 1.64-1.66, whereas they showed zero birefringence. These characteristic optical properties of the F-PSiOs come mainly from the cardo structure of the 9,9-diarylfluorene skeleton in the main chain. ${ }^{1-12}$ Thus, the F-PSiOs can unambiguously be regarded as a promising advanced material that may be applied to a variety of fields including optical material fields.

Electronic Supporting Information Available: Experimental Details, Figures S1, S2 and S3. These materials are available via. the Internet at http://www.spsj.or.jp/c5/pj/pj.htm

Received: October 9, 2008 Accepted: December 22, 2008 Published: February 12, 2009

\section{REFERENCES}

1. A. A. Askadskii, N. S. Prozorova, and L. G. Slonimskii, Vysokomol. Soedin., Ser. A, 18, 636 (1976).

2. Y. Kurosaki and T. Teramoto, Jpn. Kokai, Tokkyo Koho, 63, 182336 (1988).

3. K. Jakka, C. Chou, and C. Shu, Macromolecules, 37, 248 (2004).

4. A. K. Salunke, M. Sharma, V. Kute, and S. Banerjee, J. Appl. Polym. Sci., 96, 1292 (2005).

5. C. A. Terraza, J. Liu, Y. Nakamura, Y. Shibasaki, S. Ando, and M. Ueda, J. Polym. Sci., Part A: Polym. Chem., 46, 1510 (2008).

6. N. You, Y. Suzuki, D. Yorifuji, S. Ando, and M. Ueda, Macromolecules, 41, 6361 (2008).

7. T. Inoue, K. Fujiwara, D. Ryu, K. Osaki, M. Fuji, and K. Sakurai, Polym. J., 32, 411 (2000).

8. K. Sakurai and M. Fuji, Polym. J., 32, 676 (2000).

9. C. Badarau and Z. Y. Wang, Macromolecules, 37, 147 (2004).

10. J. Kang, J. Kim, J. Lee, and J. Kim, J. Lightwave Technol., 23, 364
(2005).

11. S. Seesukphronrarak, S. Kawasaki, K. Kobori, and T. Takata, J. Polym. Sci., Part A: Polym. Chem., 45, 3073 (2007).

12. S. Kawasaki, M. Yamada, K. Kobori, F. Jin, Y. Kondo, H. Hayashi, Y. Suzuki, and T. Takata, Macromolecules, 40, 5284 (2007).

13. T. Inada, H. Masunaga, S. Kawasaki, M. Yamada, K. Kobori, and K. Sakurai, Chem. Lett., 34, 524 (2005).

14. S. Kawasaki, M. Yamada, K. Kobori, M. Yamada, T. Kakumoto, A. Tarutani, and T. Takata, Polym. J., 39, 115 (2007).

15. S. Seesukphronrarak, S. Kawasaki, K. Kobori, and T. Takata, J. Polym. Sci., Part A: Polym. Chem., 46, 2549 (2008).

16. J. Seo, K. Cho, and H. Han, Polym. Degrad. Stab., 74, 133 (2001).

17. S. Suresh, R. J. Gulotty Jr, S. E. Bales, M. N. Inbasekaran, M. A. Chartier, C. Cummins, and D. W. Smith Jr, Polymer, 44, 5111 (2003).

18. A. Uchiyama and T. Yatabe, J. Polym. Sci., Part B: Polym. Phys., 41, 1554 (2003).

19. K. Tokumitsu, A. Tanaka, K. Kobori, Y. Kozono, M. Yamada, and K. Nitta, J. Polym. Sci., Part B: Polym. Phys., 43, 2259 (2005).

20. K. Yao, M. Koike, Y. Suzuki, K. Sakurai, T. Indo, and K. Igarashi, U. S. Patent, 6255031 (2001).

21. H. Okamura, Y. Watanabe, M. Tsunooka, M. Shirai, T. Fujiki, S. Kawasaki, and M. Yamada, J. Photopolym. Sci. Technol., 15, 145 (2002).

22. H. Okamura, K. Sakai, M. Tsunooka, M. Shirai, T. Fujiki, S. Kawasaki, and M. Yamada, J. Photopolym. Sci. Technol., 16, 87 (2003).

23. H. Okamura, C. Harada, M. Tsunooka, T. Fujiki, S. Kawasaki, M Yamada, and M. Shirai, Kobunshi Ronbunshu, 61, 75 (2004).

24. H. Okamura, K. Mitsukura, M. Shirai, T. Fujiki, M. Yamada, and S. Kawasaki, J. Photopolym. Sci. Technol., 18, 213 (2005).

25. S. Tamai, C. Tanaka, T. Abe, T. Kuroki, and J. Ishikawa, High Perform. Polym., 15, 361 (2003).

26. J. Cella and S. Rubinsztajn, Macromolecules, 41, 6965 (2008).

27. Y. Saegusa, T. Kato, H. Oshimura, and S. Nakamura, J. Polym. Sci., Part A: Polym. Chem., 30, 1401 (1992).

28. See, Supporting Information. 